Factors Associated with Attendance at a One Year Post-Cardiac Rehabilitation Risk Factor Check

Justin D. Giannoccaro ${ }^{1}$, BSc, Sandeep Aggarwal ${ }^{1,2}$, MD, Sherry L. Grace ${ }^{3,4}$, PhD, Tavis S. Campbell $^{5}, \mathrm{PhD}$, Trina Hauer ${ }^{1}, \mathrm{MSc}$, Ross Arena ${ }^{6}, \mathrm{PhD}$, Codie R. Rouleau ${ }^{1,5, *}, \mathrm{PhD}$ for the TotalCardiology Research Network ${ }^{1}$

${ }^{1}$ TotalCardiology Rehabilitation, Calgary, AB, Canada; ${ }^{2}$ Libin Cardiovascular Institute of Alberta, University of Calgary, Calgary, Alberta, Canada; ${ }^{3}$ Faculty of Health, York University, Toronto, ON, Canada; ${ }^{4}$ Knowledge, Innovation, Talent, Everywhere (KITE), University Health Network, Toronto, ON; ${ }^{5}$ Department of Psychology, Calgary, AB, Canada; ${ }^{6}$ Department of Physical Therapy, University of Illinois at Chicago, Chicago, IL *Corresponding author: 2225 Macleod Trail South, Calgary, AB, Canada, T2G 5B6, P: 403-296-6924, F: 403-571-6974, E: crouleau@totalcardiology.ca

Keywords: cardiac rehabilitation, attendance, barriers, adherence, exercise maintenance; Funding/Conflict of Interest: This research was partly funded by a grant from AstraZeneca. This source of funding had no role in study design, data collection, data analysis, interpretation of data, or in preparation of this manuscript. All authors declare no conflict of interest; Author declaration: All authors have read and approved submission of the submitted manuscript. Word count: 2000 ; Tables: 2 ; Figures: 0 ; Supplemental Digital Content: 1 ; References: 19

This is an Accepted Manuscript of an article published by Lippincott in the Journal of Cardiopulmonary Rehabilitation and Prevention in May 2020 available online: https://doi.org/10.1097/HCR.0000000000000486 


\section{Structured Abstract}

Purpose: Patients with coronary artery disease (CAD) often fail to maintain secondary prevention gains after completing cardiac rehabilitation (CR). Follow-up appointments aimed at assessing cardiac status and encouraging maintenance of health behaviors after CR completion are generally offered, but not well-attended. This study explored patient characteristics and barriers associated with non-attendance at a one-year follow-up visit following CR completion. Methods: Forty-five patients with CAD who completed a 12-week outpatient CR program but did not attend the one-year follow-up appointment were included. Participants responded to a survey consisting of open-ended questions about follow-up attendance, a modified version of the Cardiac Rehabilitation Barriers Scale, and self-report items regarding current health practices and perceived strength of recommendation to attend. Thematic analysis was used to derive categories from open-ended questionnaire responses. Linear regression was used to assess characteristics associated with appointment attendance barriers. Results: Barrier themes were: 1) lack of awareness, 2) perception of appointment as unnecessary, 3) practical or scheduling issues, 4) comorbid health issues, and 5) anticipated an unpleasant experience at the appointment. Greater self-reported barriers $(M=1.97 / 5.00 \pm 0.57)$ were significantly associated with lower perceived strength of recommendation to attend the follow-up appointment $(M=2.82 / 5.00 \pm 1.45), p=.005$. Conclusions: Providing a stronger recommendation to attend, enhancing patient awareness, highlighting potential benefits, and supporting self-efficacy might increase one-year follow-up appointment attendance and, in turn, support long-term adherence to cardiovascular risk reduction behaviors. 


\section{Condensed Abstract}

This study examined barriers to attending a follow-up visit one-year after cardiac rehabilitation to support maintained risk reduction among 45 patients. Qualitative analysis indicated awareness, perceived necessity, scheduling/health issues, and anticipated experiences were important patient considerations. Barriers were greater in those who perceived less provider encouragement to attend. 


\section{INTRODUCTION}

Cardiac rehabilitation $(\mathrm{CR})$ is a highly effective treatment for patients recovering from a range of cardiovascular conditions including coronary artery disease $(\mathrm{CAD})^{1}$. CR has been demonstrated to reduce morbidity and cardiac mortality ${ }^{2}$. These benefits are attributable to comprehensive risk reduction such as improved cardiorespiratory fitness ${ }^{3}$ and reductions in smoking, hypercholesterolemia, and blood pressure ${ }^{4}$. Despite the health benefits of CR, patients frequently have difficulty maintaining secondary prevention gains in the mos and yrs following program completion.

Though varied in frequency and duration, CR programs generally involve two-to-three sessions per wk for two-to-six $\operatorname{mos}^{5}$. Subsequently, maintenance of a complex health behavior change regimen is required for long-term optimization of cardiovascular risk ${ }^{6}$. One-yr after completing CR, many patients report decreased leisure-time physical activity relative to when they were participating in $\mathrm{CR}^{7}$ and relapses in smoking, uncontrolled hypertension, and poor lipid control ${ }^{8}$. Adherence to medications may also decrease in the mos following a cardiac event, with only $21 \%$ of cardiac patients taking prescribed beta-blockers, lipid-lowering agents, and aspirin two-yrs after initial hospitalization ${ }^{9}$. Follow-up support can promote maintenance of health behaviors ${ }^{10}$ and is offered after some CR programs to identify new cardiac issues, update exercise prescriptions, titrate medications, monitor risk factors, and revisit dietary and exercise patterns.

Although there is a comprehensive literature regarding barriers to initial CR participation $^{11}$, to our knowledge, reasons for non-attendance to follow-up care after CR have never been examined. The aims of this exploratory study were to: 1) describe patient-reported 
barriers to attending a follow-up appointment offered one-yr after completion of CR and 2) explore patient characteristics associated with barriers to follow-up attendance. A better understanding of these factors may inform strategies to improve adherence and enhance cardiovascular health following CR.

\section{METHODS}

This was a cross-sectional study conducted with CAD patients who were contacted about-but who did not attend - a follow-up appointment offered one-yr after completion of an outpatient CR program in Calgary, Canada. Ethics approval was obtained from the University of Calgary Conjoint Health Research Ethics Board. Data collection occurred between 01/2016-06/2017.

\section{CR PROGRAM \& FOLLOW-UP DESCRIPTION}

The CR program consists of twice-weekly, supervised moderate-intensity exercise sessions along with other established components for risk factor management over 12-wks. The program is offered within a Canadian city of approximately 1.2 million people. A reminder letter is sent one-yr after completing the CR program (Supplemental Digital Content 1) instructing patients to book an appointment by calling the clinic, and indicating their file will be closed if a response is not received within one-mo. Patients receive a recommendation to attend the follow-up appointment from CR staff when they enroll in the program and during the 12-wk discharge appointment.

The one-yr follow-up appointment consists of a maximal exercise test and individualized risk factor review in consultation with a program physician. Lipid profile, blood pressure, and 
anthropometric characteristics are assessed; medications are reviewed; and current smoking, diet, and exercise habits are discussed. Patients also receive an updated exercise prescription from a clinical exercise physiologist and recommendations for enhancing their exercise program.

Results and risk factor review are sent to the primary care provider. Though figures vary from yr-to-yr, unpublished data from this CR center indicate only a subset of patients who attend the CR program attends the one-yr follow-up appointment (approximately 40-50\%). Additional practices to promote maintenance of health behaviors post-CR included follow-up with primary care resources for chronic disease management, and 1:1 consultation with CR clinicians about exercise continuation upon completion of the 12-wk program.

\section{PARTICIPANTS}

Patients were contacted about the present study if they: 1) had documented CAD; 2) completed the 12-wk CR program; 3) were due to attend and had received a letter about their one-yr followup appointment within the previous three-mo; 4) did not book or attend the follow-up

appointment within one-mo of the letter being issued; and 5) provided permission to be contacted about research. Eligible patients were mailed a questionnaire package that included a consent form, questionnaires, and a pre-addressed stamped envelope. Patients were telephoned to assess their interest in study participation and to confirm they received the questionnaires. Recruitment was terminated upon theoretical saturation of qualitative data, determined by consensus between J.D.G. and C.R.R. 


\section{MEASURES}

\section{Qualitative barriers to attendance}

Three open-ended questions assessed perceived barriers to attending the one-yr follow-up appointment: 1) "What is your understanding of what happens at the one-year follow-up appointment at [the CR center]"; 2) "What are some of the reasons that you did not attend the one-year follow-up appointment?"; and 3) "What would make it more likely for you to attend the one-year follow-up appointment?’. Participants were instructed to provide as much information as possible using full sentences. Two additional questions asked how participants learned about the one-yr follow-up appointment and their perceived strength of recommendation to attend $(1=$ weak or no recommendation, 3 = moderate recommendation, $5=$ strong recommendation).

\section{Cardiac Rehabilitation Barriers Scale (CRBS $\left.{ }^{12}\right)$}

This 21-item self-report questionnaire assesses barriers to CR utilization (subscales are health care factors, logistical factors, work/time conflicts, and comorbidities). The instructions were modified to refer to attendance at the one-yr follow-up appointment, rather than initial attendance at the $\mathrm{CR}$ program. Each item was rated on a five-point scale $(1=$ strongly disagree to $5=$ strongly agree). A total barriers score was calculated using the average of all items, where higher scores indicate more barriers to attendance. CRBS subscales demonstrate acceptable internal validity (Cronbach's $\alpha=0.71-0.89$ ), test-retest reliability (intraclass correlation coefficient $=$ $.64)$, and concurrent validity with similar scales ${ }^{12}$. 


\section{Sociodemographic and health information}

Participants were asked to report their current health behaviors including tobacco use, exercise volume, and current lipid-lowering and antiplatelet medications taken. Age, sex, time since cardiac event, and number of CR sessions attended were gathered using chart review.

\section{DATA ANALYSIS}

To evaluate patient-identified barriers to follow-up attendance, thematic analysis ${ }^{13}$ was used to identify patterns within the qualitative dataset. Two researchers independently reviewed openended questionnaire responses then compared themes derived to achieve consensus through an iterative process. Incidence of each theme within the dataset was counted. Illustrative quotes were selected for each theme. To explore patient characteristics associated with barriers to CR follow-up attendance, linear regression was conducted with age, sex, time since cardiac event, and perceived strength of recommendation to attend follow-up simultaneously entered as independent variables, and the total CRBS score as the dependent variable. Health behaviors (self-reported at the time of scheduled one-yr follow-up) were analyzed using descriptive statistics.

\section{RESULTS}

Of 184 eligible patients identified, 156 were able to be contacted about the study and 45 consented and completed the questionnaires (Table 1). On average, patients were 63-yrs-old (range 40-83), predominantly male, and reported exercising at least once per wk. Although most 
(74\%) reported exercise regimens consistent with established guidelines of $\geq 150$-min per wk of aerobic exercise ${ }^{14}, 27 \%$ reported a current exercise volume of zero min per wk.

\section{QUALITATIVE REASONS FOR NON-ATTENDANCE}

Five themes were identified regarding reasons for non-attendance at the one-yr follow-up appointment (Table 2): 1) lack of awareness about the appointment (36\%), 2) perception that the appointment was unnecessary $(28 \%), 3)$ practical issues $(20 \%), 4)$ comorbid health issues $(12 \%)$, and 5) anticipation of an unpleasant experience (4\%).

\section{PATIENT CHARACTERISTICS ASSOCIATED WITH APPOINTMENT BARRIERS}

On average, perceived follow-up appointment barriers were low (CRBS $M=1.97 \pm 0.57$; Table 1). Perceived strength of recommendation to attend the appointment was weak to moderate $(M=$ $2.82 \pm 1.45)$. An examination of CRBS subscales indicated the greatest barriers to appointment attendance related to health care factors (e.g., doctor did not feel it was necessary) and work/time conflicts (e.g., travel, time constraints). In response to the sentence stem "I did not attend the one-yr follow-up appointment at cardiac rehabilitation because...”, CRBS items with the highest values included: "I already exercise at home in my community" $(M=2.79 \pm 1.47)$, "I didn’t know about the appointment (e.g., doctor didn't tell me about it)" ( $M=2.65 \pm 1.58)$, and "I don't need to attend the appointment (e.g., feel well, heart problem treated, not serious)" $(M=2.50 \pm$ 1.32). The combination of age, sex, time since cardiac event, CR session attendance, and perceived strength of recommendation accounted for $29.4 \%$ of the variance in barriers to visit attendance $(F(5,32)=2.66, P=.040)$. Sex was not an independent predictor of CRBS scores $(P$ $=.614$ ). Patients who perceived a lower strength of recommendation to attend the follow-up visit 
reported greater barriers to attendance $(b=-0.21, S E=.068, P=.005)$. There was also a trend toward patients who were relatively younger reporting greater barriers $(b=-0.02, S E=.009, P=$ $.062)$.

\section{DISCUSSION}

Underutilization of CR is a well-documented problem ${ }^{15}$ but most research to date has focused on barriers to referral, enrolment, and program adherence. This preliminary study is the first to examine reasons for underutilization later in the cardiac care trajectory by characterizing barriers to accessing a follow-up assessment one-yr post-CR. Long-term adherence to healthy lifestyle behaviors and prescribed medications is essential to the improved outcomes that can be achieved through CR participation. Given the frequent difficulty maintaining a favorable risk factor profile in the mos and yrs after a cardiac event ${ }^{7,8}$, problems with follow-up attendance could limit the magnitude of long-term health benefits accrued during CR.

The present qualitative findings are consistent with recommendations to address patient-, provider- and system-level factors to improve CR participation ${ }^{16}$. Receiving encouragement to attend CR by a health care provider represents a robust predictor of enrollment and attendance ${ }^{17}$, whereas the average strength of recommendation to attend a CR follow-up visit was perceived by patients as only weak-to-moderate in this study. In addition, lack of awareness about the appointment was associated with non-attendance. This could have been due to a variety of factors including miscommunication about the follow-visit or patients moving to a new address (and not receiving the reminder letter) after CR completion. Some participants reported that lack of perceived necessity, practical issues, and comorbid conditions had deterred them from 
booking a CR follow-up appointment. Efforts to increase awareness about CR follow-up while providing more encouragement to attend could help patients access this potentially important service.

A possible limitation of this study is lack of generalizability. This small sample may not be representative of patients one-yr post-CR. A larger sample may have captured opinions from more diverse patients and facilitated nuanced subgroup analyses. Potential sex differences warrant further attention, given that females are less likely to attend $\mathrm{CR}^{18}$. Also, a slightly greater proportion of males participated in the present study compared to males who complete this CR program in general $^{18}$, indicating females may be unrepresented in this sample. The scope of this study precluded an assessment of patients who opted not to participate in the present survey and patients who do attend the one-yr follow-up visit. Future research could compare characteristics of appointment attendees versus non-attendees. Results are also from a single center and require replication in other settings. The response rate was low, which could cause selection/nonresponse biases, though this should be less of a concern given non-attendance was under investigation. Although we did observe that exercise volume, usage of cardioprotective medications, and rates of tobacco abstinence were high, follow-up visits could further improve adherence. However, only self-reported health practices were measured and may not correspond to objective indices of adherence. Whereas prior research has reported a positive effect of follow-up occurring up to three-yrs following $\mathrm{CR}^{19}$, the efficacy and cost-effectiveness of $\mathrm{CR}$ follow-up appointments for enhancing cardiac outcomes and adherence has yet to be established.

A strength of the present methodology is the emphasis on formative, patient-oriented research to inform strategies to address patient non-adherence. We are currently using the collected data to tailor internal clinic processes to target patient-identified barriers through 
systematic reminder calls, pre-booking the one-yr visit, electronic communications, and consistent messaging regarding the one-yr follow-up. Future work in this area might identify the optimal timing of CR follow-up care, recognize patients who are having difficulty with longterm disease management, and help patients sustain the health benefits achieved during CR. 


\section{ACKNOWLEDGEMENTS}

The authors thank Devin Aggarwal for his assistance with recruitment, data entry, and review of the manuscript, and Leslie Austford for her assistance with reviewing the manuscript. 
Table 1

Sample Characteristics $(N=45)$

Variable
Sociodemographic Characteristics

Age, $Y r$

Male

\section{Clinical Characteristics}

Primary Cardiac Diagnosis

STEMI

NSTEMI

Angina

Cardiomyopathy

Ischemic Heart Disease

Chronic Stable CAD

Aortic Regurgitation

Time Since Index Cardiac Event, $M o$

Exercise Frequency ${ }^{\mathrm{b}}$, Sessions per wk

Exercise Duration ${ }^{\mathrm{b}}$, Min per session

Current Tobacco Use ${ }^{b}$

Current Use of Heart Rate Monitor During Exercise ${ }^{b}$

Current Cardiac Medications Taken ${ }^{\mathrm{b}}$

Cholesterol-Lowering Medication (Any)

Rosuvastatin

Atorvastatin

Simvastatin

Pravastatin

Ezetimide

Antiplatelet Medication (Any)

Clopidogrel
$63.24 \pm 10.04$

$40(88.9)$

$M \pm S D$ or $n(\%)$

14 (31.1)

9 (20.0)

14 (31.1)

3 (6.7)

$3(6.7)$

$1(2.2)$

$1(2.2)$

$23.28 \pm 2.88$

$2.90 \pm 2.19$

$32.21 \pm 31.25$

$2(4.4)$

16 (35.6)

39 (86.7)

13 (28.9)

21 (46.7)

0 (0)

3 (6.7)

4 (8.9)

41 (91.1)

8 (17.8) 


\begin{tabular}{lc}
\hline Ticagrelor & $6(13.3)$ \\
Aspirin & $40(88.9)$
\end{tabular}

\section{CR-Related Characteristics}

$\begin{array}{ll}\text { Total Barriers, CRBS } & 1.97 \pm 0.57\end{array}$

$\begin{array}{ll}\text { Perceived Need/Healthcare Barriers } & 2.25 \pm 0.68\end{array}$

$\begin{array}{ll}\text { Logistic Barriers } & 1.57 \pm 0.73\end{array}$

$\begin{array}{ll}\text { Work/Time Barriers } & 2.09 \pm 1.07\end{array}$

$\begin{array}{ll}\text { Comorbidities } & 1.74 \pm 0.77\end{array}$

CR Attendance ${ }^{\mathrm{a}}$, \# Sessions $\quad 18.97 \pm 0.44$

Perceived Strength of Recommendation to Attend, 1-5 Scale $\quad 2.82 \pm 1.45$

How did you find out about the one-yr appointment

Information Package 24 (53.3)

I Did Not Find Out $\quad 8$ (17.8)

Cardiologist $\quad 5(11.1)$

Other $5(11.1)$

Note. CAD = Coronary Artery Disease, $\mathrm{CRBS}=$ Cardiac Rehabilitation Barriers Scale, STEMI $=$ ST-Elevation Myocardial Infarction, NSTEMI = Non-ST-elevation myocardial infarction.

${ }^{\mathrm{a}} n=37$. Excludes participants who attended home-based CR program. Total prescribed number of sessions is $24 .{ }^{\mathrm{b}}$ As reported by patients within three-mo of missed one-yr follow-up visit. 
Table 2

Themes Identified Regarding Reasons for Non-Attendance at a One-Yr Post-Cardiac

Rehabilitation Follow-Up Appointment $(N=45)$

\begin{tabular}{|c|c|c|}
\hline Theme & Elaboration & Exemplar Quotes \\
\hline $\begin{array}{l}\text { Lack of } \\
\text { awareness }\end{array}$ & $\begin{array}{l}\text { Patient did not attend due to a lack of knowledge } \\
\text { about being due to attend a one-yr follow-up } \\
\text { appointment or about the necessary steps to book } \\
\text { the appointment. }\end{array}$ & $\begin{array}{l}\text { "I was not aware there was a } \\
\text { follow-up appointment." } \\
\text { "I was waiting for a call." }\end{array}$ \\
\hline $\begin{array}{l}\text { Perceived } \\
\text { appointment as } \\
\text { unnecessary }\end{array}$ & $\begin{array}{l}\text { Patient knew about the appointment but did not } \\
\text { book because they felt the appointment was of no } \\
\text { personal benefit. }\end{array}$ & $\begin{array}{l}\text { “...my family doctor said I } \\
\text { did not need this appointment } \\
\text { because I just had tests at } \\
\text { [other clinic]" } \\
\text { "[I] feel healthy. Don't feel } \\
\text { that it was necessary." }\end{array}$ \\
\hline $\begin{array}{l}\text { Practical or } \\
\text { scheduling } \\
\text { issues }\end{array}$ & $\begin{array}{l}\text { Patient knew about the appointment but did not } \\
\text { book due to concerns about scheduling, } \\
\text { transportation, or other logistical problems. }\end{array}$ & $\begin{array}{l}\text { "Timing and work schedule" } \\
\text { "[I] had to work, started a } \\
\text { new job." }\end{array}$ \\
\hline $\begin{array}{l}\text { Comorbid } \\
\text { health issues }\end{array}$ & $\begin{array}{l}\text { Patient knew about the appointment but did not } \\
\text { book due to the presence of other health problems. }\end{array}$ & $\begin{array}{l}\text { "The main and only reason [I } \\
\text { did not attend] is that I now } \\
\text { have sternum instability..." }\end{array}$ \\
\hline $\begin{array}{l}\text { Anticipated } \\
\text { unpleasant } \\
\text { experience }\end{array}$ & $\begin{array}{l}\text { Patient was aware of appointment but did not } \\
\text { attend because they perceived the appointment } \\
\text { would be aversive in some way. }\end{array}$ & $\begin{array}{l}\text { "I find these stress tests very } \\
\text { stressful." }\end{array}$ \\
\hline
\end{tabular}




\section{REFERENCES}

1. Leon AS, Franklin BA, Costa F, et al. Cardiac rehabilitation and secondary prevention of coronary heart disease: An American Heart Association Scientific Statement From the Council on Clinical Cardiology (Subcommittee on Exercise, Cardiac Rehabilitation, and Prevention) and the Council on Nutrition, Physical Activity, and Metabolism (Subcommittee on Physical Activity), in Collaboration With the American Association of Cardiovascular and Pulmonary Rehabilitation. Circulation. 2005;111(3):369-376.

2. Anderson L, Oldridge N, Thompson DR, et al. Exercise-Based Cardiac Rehabilitation for Coronary Heart Disease: Cochrane Systematic Review and Meta-Analysis. J Am Coll Cardiol. 2016;67(1):1-12.

3. Martin BJ, Arena R, Haykowsky M, et al. Cardiovascular fitness and mortality after contemporary cardiac rehabilitation. Mayo Clin Proc. 2013;88(5):455-463.

4. Oldridge N. Exercise-based cardiac rehabilitation in patients with coronary heart disease: meta-analysis outcomes revisited. Future Cardiol. 2012;8(5):729-751.

5. Chaves G, Turk-Adawi K, Supervia M, Santiago Pio C, Mamataz T, Abdel-Hadi R, Lopez-Jiminez F, El-Heneidi AA, Grace SL. Cardiac rehabilitation dose around the globe: Variation and drivers. Circ Cardiovasc Qual Outcomes. In press.

6. Dugmore LD, Tipson RJ, Phillips MH, et al. Changes in cardiorespiratory fitness, psychological wellbeing, quality of life, and vocational status following a 12 month cardiac exercise rehabilitation programme. Heart. 1999:359-366.

7. Smith PJ, Sherwood A, Mabe S, Watkins L, Hinderliter A, Blumenthal JA. Physical activity and psychosocial function following cardiac rehabilitation: One-year follow-up of 
the ENHANCED study. Gen Hosp Psychiatry. 2017;49(919):32-36.

8. Willich SN, Müller-Nordhorn J, Kulig M, et al. Cardiac risk factors, medication, and recurrent clinical events after acute coronary disease: A prospective cohort study. Eur Heart J. 2001;22(4):307-313.

9. Ho PM, Bryson CL, Rumsfeld JS. Medication adherence: Its importance in cardiovascular outcomes. Circulation. 2009;119(23):3028-3035.

10. Mittag O, China C, Hoberg E, et al. Outcomes of cardiac rehabilitation with versus without a follow-up intervention rendered by telephone (Luebeck follow-up trial): overall and gender-specific effects. Int J Rehabil. 2006;29(4):295-302.

11. Ruano-Ravina A, Pena-Gil C, Abu-Assi E, et al. Participation and adherence to cardiac rehabilitation programs. A systematic review. Int J Cardiol. 2016;223:436-443.

12. Shanmugasegaram S, Gagliese L, Oh P, et al. Psychometric validation of the Cardiac Rehabilitation Barriers Scale. Clin Rehabil. 2012;26(2):152-164.

13. Braun V, Clarke V. Using thematic analysis in psychology. Qual Res Psychol. 2006;3(2):77-101.

14. U.S. Department of Health and Human Services. Physical Activity Guidelines for Americans, 2nd Edition. Washington, D.C.; 2018.

15. Grace SL, Turk-Adawi K, Santiago de Araújo Pio C, Alter DA. Ensuring Cardiac Rehabilitation Access for the Majority of Those in Need: A Call to Action for Canada. Can J Cardiol. 2016;32(10):S358-S364.

16. Thomas RJ, Beatty AL, Beckie TM, et al. Home-based cardiac rehabilitation: A scientific statement from the American Association of Cardiovascular and Pulmonary Rehabilitation, the American Heart Association, and the American College of Cardiology. 
Circulation. 2019;140:e69-89.

17. Gravely-Witte S, Leung YW, Nariani R, et al. Effects of cardiac rehabilitation referral strategies on referral and enrollment rates. Nat Rev Cardiol. 2010;7(2):87-96.

18. Martin B, Hauer T, Arena R, et al. Cardiac rehabilitation attendance and outcomes in coronary artery disease patients. Circulation. 2012;126:677-687.

19. Giannuzzi P. Global Secondary Prevention Strategies to Limit Event Recurrence After Myocardial Infarction. Arch Intern Med. 2008;168(20):2194. 